\title{
INTRAOSSEOUS HYPERTENSION AND PAIN IN THE KNEE
}

\author{
Carl C. Arnoldi, Rudolf K. Lemperg and Håkan Linderholm
}

From the Departments of Orthopaedic Surgery, University Hospitals of Copenhagen, Denmark, and Umeå, Sweden, and the Department of Clinical Physiology, University Hospital, Umeà, Sweden

\begin{abstract}
The intraosseous pressure in the femur and tibia near the knee and in the internal saphenous vein at knee level was measured in fifty-three patients with suspected knee lesions. There were four groups: with and without degenerative osteoarthritis and with and without aching rest pain of the knee region. Low intraosseous pressures were found in patients with neither osteoarthritis nor rest pain, and in half the patients with osteoarthritis but without rest pain. Low pressures were found in the tibia, but very high intraosseous pressures were found in the femur in most patients with osteoarthritis and rest pain. Patients with no osteoarthritis but with rest pain mostly had high pressures in both the tibia and the femur.
\end{abstract}

In patients with degenerative osteoarthritis of the hip or knee there is a disturbance of venous drainage from juxtachondral cancellous bone marrow with intraosseous stasis (Mériel, Ruffié and Fournié 1955; Phillips 1966) and hypertension (Arlet, Ficat and Sebbag 1968; Arnoldi, Linderholm and Müssbichler 1972). The characteristic rest pain of severe osteoarthritis may be the result of intraosseous hypertension. Usually such pain disappears when the high medullary pressure is released by osteotomy or cortical fenestration (Arnoldi, Lemperg and Linderholm 1971). However, constant aching pain of the same character-independent of joint movement or loadingoccurs in some patients who have no clinical or radiological signs or degenerative arthritis.

The present investigation was done to ascertain whether or not pain at rest is associated with increased intraosseous pressure. It also contributes to the understanding of the relationship between pain, intraosseous pressure and osteoarthritis.

\section{MATERIAL}

The clinical material consisted of thirty-six men and seventeen women admitted to hospital during the years 1971 to 1973 for suspected lesions of the semilunar cartilages or loose bodies in the knee.

Before operation, which was done on all patients, radiographs of the knees were taken with the patient standing. At arthrotomy the state of the articular cartilage in the medial, lateral and patello-femoral compartments was assessed by eye. The presence of erosion was taken as evidence of osteoarthritis.

Before operation the type of pain felt by the patient was fully assessed. Most patients had had typical episodes of locking of the knee with acute pain or discomfort. Some patients had no pain at rest between the episodes of locking, but some had pain on movement or weightbearing. Other patients had rest pain. The presence or absence of both rest pain and osteoarthritis allowed the patients to be divided into four groups (Table I).

No patient in this series had osteoarthritis of the hip or heart failure.

\section{METHODS}

Measurements of intramedullary and peripheral venous pressure-The patients were examined under local or general anaesthesia in the supine position. Specially constructed conical cannulae (made by AB Stille-Werner, Stockholm) 15 centimetres long, with an external diameter of 4.55 millimetres at the tip and a lumen measuring 2.60 millimetres, were introduced into the distal part of the femur and the proximal part of the tibia. A polyethylene catheter (P 90) was inserted into the saphenous vein with its tip at the level of the joint. The catheter in the vein and the needles in the bone marrow were connected to infusion drips of saline that were continuedexcept during periods of pressure measurement-until the end of the examination.

Pressure measurements-Polyethylene catheters were fitted to the needles in the bone marrow and the tubes and the catheter in the saphenous vein were connected to a recording system for pressure curves (Mingograph, Elema) with paper speed of 5 millimetres per second. The recording system gave deflections proportional to the pressures applied within the range of measurements and-tested with a sine wave pressure of varying frequency-the amplitude was correctly recorded to about 15 cycles per second.

A point at the intersection of the midaxillary line with a plane, perpendicular to the long axis of the body and through the fourth costal insertion at the sternum

Professor C. Arnoldi, M.D., Rigshospitalet, Blegdamsvej 9, 2100 Copenhagen Ø, Denmark.

Professor Rudolf K. Lemperg, M.D., Department of Orthopaedic Surgery, University Hospital, Umeå, Sweden. Professor Håkan Linderholm, M.D., Department of Clinical Physiology, University Hospital, Úmeå, Sweden. 
TABLE I

Age, Sex and Grouping of the Patients

Groups

Without osteoarthritis

With osteoarthritis

\begin{tabular}{|c|c|c|c|c|c|}
\hline & A-without rest pain & B-with rest pain & C-without rest pain & D-with rest pain & Total \\
\hline & 15 male & 7 male & 9 male & 5 male & \\
\hline Number of patients & $16 \quad 1$ female & 10 female & 2 female & 4 female & 53 \\
\hline Average age in years & $34 \cdot 6$ & $35 \cdot 7$ & $44 \cdot 0$ & $51 \cdot 8$ & \\
\hline Mean age range in years & $17-70$ & $21-54$ & $21-63$ & $25-73$ & \\
\hline
\end{tabular}

TABLE II

Mean Pressures in the Saphenous Vein and Intramedullary Pressures in the Proximal Tibial and Distal Femoral Epiphyses in Patients with and without Pain at Rest and Osteoarthritis Respectively

The pressures in the tibia and femur are given in relation to venous pressure.

The difference between pressures in the tibia and femur is also given. In the column "maximal pressure" the highest mean pressure in the femur or tibia is given. Further, the number of patients is given having the maximal pressure in the femur or in the tibia.

\begin{tabular}{|c|c|c|c|c|c|c|c|c|}
\hline \multirow[b]{2}{*}{ Group } & \multirow{2}{*}{$\begin{array}{l}\text { Number } \\
\text { of } \\
\text { patients }\end{array}$} & \multirow[b]{2}{*}{$\mathbf{P}$ vein } & \multirow[b]{2}{*}{ P tibia } & \multirow[b]{2}{*}{$P$ femur } & \multirow[b]{2}{*}{ DP } & \multirow{2}{*}{$\begin{array}{l}\text { P of maximal } \\
\text { pressure in } \\
\text { tibia or } \\
\text { femur }\end{array}$} & \multicolumn{2}{|c|}{$\begin{array}{l}\text { Number of patients with } \\
\text { maximal pressure in }\end{array}$} \\
\hline & & & & & & & tibia & femur \\
\hline \multicolumn{9}{|c|}{ Without osteoarthritis } \\
\hline A-without pain & 16 & $\begin{array}{l}10 \cdot 1 \pm 1 \cdot 3 \\
(3 \cdot 8-22 \cdot 3)\end{array}$ & $\begin{array}{l}9 \cdot 8 \pm 2 \cdot 1 \\
(1 \cdot 1-30 \cdot 0)\end{array}$ & $\begin{aligned} 8 \cdot 6 & \pm 1 \cdot 8 \\
(0 & -19 \cdot 8)\end{aligned}$ & $1 \cdot 2 \pm 1 \cdot 6$ & $\begin{array}{l}11 \cdot 6 \div 2 \cdot 1 \\
(1 \cdot 1-30 \cdot 0)\end{array}$ & 10 & 6 \\
\hline B-with pain & 17 & $\begin{array}{l}11 \cdot 0 \pm 1 \cdot 7 \\
(1 \cdot 0-29 \cdot 1)\end{array}$ & $\begin{array}{l}31.9 \pm 5.0 \\
(5 \cdot 1-78.9)\end{array}$ & $\begin{array}{l}28 \cdot 4 \pm 4 \cdot 1 \\
(4 \cdot 1-59 \cdot 1)\end{array}$ & $3 \cdot 5 \pm 5 \cdot 4$ & $\begin{array}{l}39.5 \pm 4.3 \\
(5.4-78.9)\end{array}$ & 10 & 7 \\
\hline \multicolumn{9}{|l|}{ With osteoarthritis } \\
\hline C-without pain & 11 & $\begin{array}{l}11 \cdot 3 \pm 1 \cdot 6 \\
(5 \cdot 9-24 \cdot 7)\end{array}$ & $\begin{array}{l}13 \cdot 1 \pm 3 \cdot 1 \\
(0 \cdot 3-38 \cdot 2)\end{array}$ & $\begin{array}{l}13 \cdot 4=3 \cdot 0 \\
(0 \cdot 3-28 \cdot 9)\end{array}$ & $0 \cdot 3=3 \cdot 7$ & $\begin{array}{l}17 \cdot 9=3 \cdot 3 \\
(1 \cdot 7=38 \cdot 2)\end{array}$ & 5 & 6 \\
\hline D-with pain & 9 & $\begin{array}{l}12 \cdot 1 \div 1 \cdot 8 \\
(3 \cdot 1-23 \cdot 3)\end{array}$ & $\begin{aligned} 12 \cdot 5 & \pm 4 \cdot 0 \\
(0 & 35 \cdot 2)\end{aligned}$ & $\begin{array}{l}24 \cdot 7 \pm 4 \cdot 7 \\
(2 \cdot 9-46 \cdot 4)\end{array}$ & $12 \cdot 2+7 \cdot 6$ & $\begin{array}{c}30 \cdot 3 \pm 3 \cdot 2 \\
(16 \cdot 2-46 \cdot 4)\end{array}$ & 2 & 7 \\
\hline
\end{tabular}

$\mathbf{P}=$ mean pressure $\quad$ S.E. standard error of the mean.

$\mathrm{DP}=$ mean pressure difference between tibia and femur \pm S.E. Ranges are given within brackets-all pressures are given in millimetres $\mathbf{~ H g}$.

TABLE III

The Mean Differences of Intraosseous Pressures in Tibia, Femur and the Maximal Pressures in the Tibia or Femur between the Groups Specified in Table II

\begin{tabular}{lllllll}
\hline Groups & & Tibia & & & \multicolumn{2}{c}{ Maximal in } \\
B-A & +22.1 & $\mathbf{P}<0.001$ & +19.8 & $\mathbf{P}<0.001$ & +27.9 & $\mathbf{P}<0.001$ \\
D-A & +2.7 & Not significant & +16.1 & $\mathbf{P}<0.001$ & +18.7 & $\mathbf{P}<0.001$ \\
C-A & +3.3 & Not significant & +4.8 & Not significant & +6.3 & Not significant \\
D-C & +0.6 & Not significant & -11.3 & $\mathbf{P} 0.05$ & -12.4 & $\mathbf{0 . 0 1}<\mathbf{P}<0.02$ \\
B-D & +19.4 & $\mathbf{0 . 0 1 < P < 0 . 0 2}$ & +3.7 & Not significant & +9.2 & Not significant \\
B-C & +18.8 & $\mathbf{0 . 0 0 1 < P < 0 . 0 1}$ & +15.0 & $\mathbf{0 . 0 1}<\mathbf{P}<0.02$ & +21.6 & $\mathbf{P}<0.001$ \\
\hline
\end{tabular}

$\mathbf{P}$ is the probability that the difference is caused by chance. 
of the supine patient, was chosen to indicate heart level, which was the common reference level for all pressure measurements.

\section{RESULTS}

Table II shows venous and intraosseous pressures in the four groups of patients and Table III shows the differences between the intraosseous pressures of the groups and their statistical significance.

Venous pressure-The pressure in the saphenous vein was within the range expected and there were no differences between the groups.

Intraosseous pressure-Fourteen of the sixteen patients with no osteoarthritis and no rest pain (group A) had normal intraosseous pressure measured in the cancellous bone, viz., 2-12 millimetres of mercury above the pressure in the adjacent peripheral vein (Arnoldi and Linderholm 1966). Similar normal values were found in six out of eleven patients with osteoarthritis but no rest pain (group C). In seven patients out of nine with osteoarthritis and rest pain (group D) low pressures were found in the tibia, but in six of them abnormally high intraosseous pressures were recorded in the femur (Table II). In contrast, high pressures were found in fifteen out of seventeen patients with no osteoarthritis but with rest pain (group B) in either or both the tibia and femur. Of this group five patients had anatomically normal knees with neither meniscus injury nor loose bodies. Three of these five patients had insufficient venous perforants in the lower leg. In patients with rest pain and osteoarthritis (group D) the highest pressure was usually found in the femur, but it was equally distributed between the femur and tibia in patients with rest pain but with no osteoarthritis (group B). In patients in group D the difference between the pressures in the tibia and femur was not statistically significant.

\section{DISCUSSION}

Venous engorgement and intraosseous hypertension in degenerative osteoarthritis-Patients with severe degenerative osteoarthritis of the hip and knee have impaired venous drainage from the juxtachondral cancellous bone across the cortex, and intraosseous phlebography will reveal more or less complete disappearance of the normal drainage routes with delayed emptying of the contrast medium from the medullary cavity (Mériel $e t$ al. 1955; Phillips 1966; Arlet et al. 1968; Arnoldi et al. 1972). Intact or perhaps increased arterial supply (Harrison, Schajowicz and Trueta 1953) combined with increased resistance to venous outflow are probably the factors responsible for the intramedullary hypertension recently observed in osteoarthritis by several authors (Arnoldi $e t$ al. 1971; Arlet et al. 1968; Arnoldi et al. 1972). At present the cause of the impairment of the venous drainage is obscure. It must be assumed that the pathological process is located in or near the cortex.

Intraosseous hypertension in patients without osteo-
arthritis-Before the present investigation, intramedullary stasis and hypertension had only been described in the cancellous bone of osteoarthritic joints. It is shown here, however, that intraosseous hypertension of the same magnitude may occur in knees that have no signs of osteoarthritis. Further, pain at rest in the lower leg and or near the knee was also found in five patients without lesions of the semilunar cartilages or loose bodies of the joint and might be called idiopathic intraosseous hypertension, although three of the five patients had also an insufficiency of the venous perforants of the lower leg; in the latter it is possible that the intraosseous hypertension was part of a generalised condition. Preliminary results of intraosseous phlebography done on patients with intraosseous hypertension in the tibia or the femur suggest a similar picture of impaired drainage and delayed emptying of contrast from the medullary vessels as has been found in patients with severe osteoarthritis of the hip (Arnoldi et al. 1972).

Relationship between intraosseous hypertension, rest pain and osteoarthritis-Earlier investigations on intraosseous pressure in selected patients with osteoarthritis of the hip severe enough to warrant operation (Arnoldi et al. 1971; Arnoldi et al. 1972) showed that the symptom that made the patients seek treatment was pain, mostly a severe aching pain at rest. A close relationship was found between the amounts of intraosseous hypertension and rest pain. Patients with an intraosseous pressure of above 40 millimetres of mercury had rest pain while those with pressures below 35 millimetres of mercury did not. As in the 1972 study the pressure in the femoral vein was about 12 millimetres of mercury, the intraosseous pressure at the hip should be reduced by that amount to conform to the present study. This brings it to 28 millimetres of mercury, but neither this nor the results of the present study indicate that there is a sharp limit of 28 millimetres of mercury above which pain is present and below which pain is absent. There is considerable overlapping of pressure values in the various groups of patients, whether with or without pain. Possibly there were other causes of pain in some patients. In general, however, the intraosseous pressure in the groups with pain was higher than in those without pain, independent of the presence or absence of osteoarthritis.

In the patients with pain, but with no osteoarthritis (group B), the pressure was high both in tibia and femur. In contrast, in the patients with both pain and osteoarthritis (group D) the pressure in the tibia was usually comparatively low, while that in the femur usually was high (Tables II and III).

The results show that there is a relationship between the presence of pain and intraosseous hypertension, but that there is no relationship between increased intraosseous pressure and the presence of osteoarthritis.

Intraosseous hypertension-precursor of osteoarthritis? Chronic intraosseous hypertension, probably caused by increased resistance to venous outflow, may alter the 


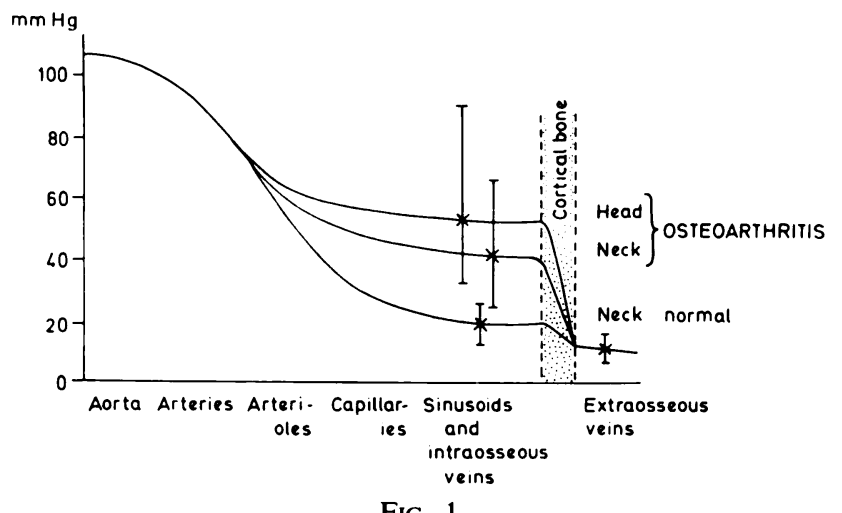

FIG. 1

Schematic representation of intraosseous pressures and pressure in the femoral vein from patients with severe unilateral osteoarthritis of the hip joint (Arnoldi, Linderholm and Müssbichler 1972).

capillary blood flow and therefore the nutrition in bone. There are indications that the intramedullary pressure in osteoarthritic hips is highest in the cancellous juxtachondral bone and falls gradually towards the diaphysis (Arnoldi et al. 1972). Figure 1 shows diagrammatically the intraosseous pressures from normal hips and from the head and neck of the femur in patients with severe unilateral osteoarthritis. It seems obvious that the capillary blood flow should suffer from a decreased pressure difference across the capillary bed. Other investigations indicated that prolonged intraosseous hypertension caused by repeated high pulses of venous pressure may lead to changes in the structure of cortical as well as cancellous bone, such as osteosclerosis or increased radiodensity and formation of osteophytes (Brookes and Helal 1968; Arnoldi, Linderholm and Vinnerberg 1972).

In the present series the patients of group B generally belong to a younger age group than the patients with osteoarthritis (groups C and D). If hypoxia of the intraosseous tissue is present in intraosseous hypertension and is maintained for a considerable time, it is possible that osseous changes similar to those of osteoarthritis could develop in these patients. Thus, circulatory changes in the subchondral bone might be the primary aetiological factor in at least some forms of degenerative osteoarthritis. The answer to this question may have practical consequences.

In patients with osteoarthritis and typical rest pain osteotomy or cortical fenestration is accompanied by an immediate fall of intraosseous pressure and generally by prompt disappearance of rest pain (Arnoldi et al. 1971). If the hypothesis holds true that intraosseous hypertension is one of the precursors of osteoarthritis such surgical procedures might be considered as prophylactic measures.

This work was supported by grants from the Swedish Medical Research Council, project number B72-17C-2337-05A, and the Danish Medical Research Council, project number 512-3293.

\section{REFERENCES}

Arlet, J., Ficat, P., and Sebbag, D. (1968) Intérêt de la mesure de la pression intra-médullaire dans le massif trochantérien chez l'homme, en particulier pour le diagnostic de l'ostéonécrose fémoro-capitale. Revue du Rhumatisme et des Maladies Ostéo-articulaires, 35, $250-256$.

Arnoldi, C. C., Lemperg, R. K., and Linderholm, H. (1971) Immediate effect of osteotomy on the intramedullary pressure of the femoral head and neck in patients with degenerative osteoarthritis. Acta orthopaedica Scandinavica, 42, 454-455.

Arnoldi, C. C., and Linderholm, H. (1966) Intraosseous pressure of the calcaneus and venous pressure in the calf of healthy human subjects in the erect position. Acta chirurgica Scandinavica, 132, 464-662.

Arnoldi, C. C., Linderholm, H., and Müissbichler, H. (1972) Venous engorgement and intraosseous hypertension in osteoarthritis of the hip. Journal of Bone and Joint Surgery, 54-B, 409-421.

Arnoldi, C. C., Linderholm, H., and Vinnerberg, A. (1972) Skeletal and soft tissue changes in the lower leg in patients with intracalcanean hypertension. Acta chirurgica Scandinavica, 138, 25-37.

Brookes, M., and Helal, B. (1968) Primary osteoarthritis, venous engorgement and osteogenesis. Journal of Bone and Joint Surgery, 50-B, 493-504.

Harrison, M. H. M., Schajowicz, F., and Trueta, J. (1953) Osteoarthritis of the hip: a study of the nature and evolution of the disease. Journal of Bone and Joint Surgery, 35-B, 598-626.

Mériel, P., Ruffié, R., and Fournié, A. (1955) La phlebographie de la hanche dans les coxarthroses. Revue de Rhumatisme et des Maladies Ostéo-articulaires, 22, 238-241.

Phillips, R. S. (1966) Phlebography in osteoarthritis of the hip. Journal of Bone and Joint Surgery, 48-B, 280-288. 